LBL --25768

DE89 013371

\title{
Pressure-driven Brine Migration in a Salt Repository
}

Y. Hwang, P. L. Chambrê, T. H. Pigford, and W. W.-L. Lee

Department of Nuclear Engineering

University of California

and

Earth Sciences Division,

Lawrence Berkeley Laboratory

1 Cyclotron Road

Berkeley, CA 94720

January 1989

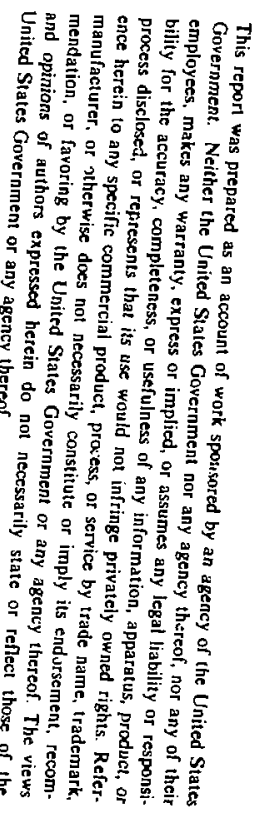

Work supported in part by the Dirctor, Omice of Civilian Radioactive Waste Management, Omice of Systems Integration and Regulations, Licensing and Compliance Division, of the $U$. S. Department of Energy under contract DE-AC03-76SF00098. 
The authors invite comments and would appreciate being notified of any errors in the report.

T. H. Pigford Department of Nuclear Engineering

University of California

Berkeley, CA 94720 


\section{Contents}

1. Introduction . . . . . . . . . . . . . . . . . . . . . . 1

2. Analysis . . . . . . . . . . . . . . . . . . . . . 2

2.1 Temperature Field . . . . . . . . . . . . . . . . . . . . . . 4

2.2 Case 1: Open Borehole. . . . . . . . . . . . . . . . . . . . . . . . . . .

2.3 Case 2 : Consolidated Salt . . . . . . . . . . . . . . . . . . . . . . . . . 8

3. Numerical Illustrations . . . . . . . . . . . . . . . . . . . . . . . . . . . . . . . . 11

3.1 Temperature Profile . . . . . . . . . . . . . . . . . . . . . . . . . . . . . . 12

3.2 (ase 1: Brine Migration into an Open Borchole . . . . . . . . . . . . . . . . It

3.3 Case 2: Brine Migration in Consolidated Salt . . . . . . . . . . . . . . . . . . . 19

1. Comparison of Advective and Diffusive Radionuclide Transport . . . . . . . . . . . . . . . 23

5. Conclusions . . . . . . . . . . . . . . . . . . . . . . . . . . . 27

References. . . . . . . . . . . . . . . . . . . . . 27

\section{List of Figures}

Figure I. Elevation Schenatic, Open Borehole . . . . . . . . . . . . . . . . . . . . . . . . . 3

Figure 2. Comparison of Fitted versus Actual Heat Flux . . . . . . . . . . . . . . . . . . . . . 13

Figure 3. Relative Tenperat ure in Salt after Emplacement . . . . . . . . . . . . . . . . . . . 14

Figure 4. Relative 'Temperature at Waste Surface After Emplacernent . . . . . . . . . . . . 15

Figure 5. Brine Migration Velocity into an Open Borehole . . . . . . . . . . . . . . . . . . . 17

Figure 6. Cumulative Brine Flows into an Open Borehole . . . . . . . . . . . . . . . . . 18

Figure 7 . Pressure Profile in Consolidated Salt . . . . . . . . . . . . . . 20

Figure 8. Brine Migration Velocities in Consolidated Salt . . . . . . . . . . . . . . . . . . 21

Figure 9. Sensitivity of Brine Migration Velocity to Sall Permeability . . . . . . . . . . . . . . 22

Figure 10. Mass Flux Rate by Advection and Molecular Diffusion . . . . . . . . . . . . . . . . . 24

Figure 11 . Comparison of Mass Flu Rate at Early Time . . . . . . . . . . . . . . 25

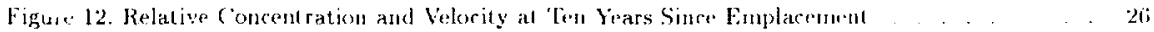




\section{Introduction}

'The' traditional view is that salt is the ideal rock for isolation of nuclear waste because $\mathrm{u}$ is "dry" and probahly "impermeable." The existence of salt through geologic time is prima facie evidence of such properi.ies. Experiments and experjence at potential salt sites for geologic repositories have indicated that while porosity and permeability of salt are low. the salt may be saturated with brine. ${ }^{1}$ If this hypothesis is correct. then it is possible to have brine flow due to pressure differences within the salt. If there is pressure-driven brine migration in salt repositories then it is paramount to know the magnitude of such flow because inwars brine flow would affect the corrosion rate of nuclear waste containers and outward hrine fow might affect radionuclide transport rates.

Brine exists in natural salt as inclusions in salt erystals and in grain boundaries. Brine inclusions in crystals move to nearby grain boundaries when subjected to a temperature gradient, because of tenperaturedependent solubility of salt. Brine in grain boundaries moves under the infuence of a pressure gradient. ${ }^{1,2}$ When salt is mined to create a waste repository, brine from grain boundaries will migrate into the rooms, tunnels and boreholes hecause these cavities are at atmospheric pressure. After a heat-emitting waste package is emplaced and hackfilled, the heat will impose a temperature gradient in the surrounding salt that will cause inclusions in the nearby salt to migrate to grain boundaries wittin a few years, adding to the brine that was already present in the grain boundaries.

Until the heated salt immediately adjacent to the waste package has consolidated, brine can accumulate in the amnular space between the container and the emplacement hole wall. This brine movernint is due to the difference in brine pressure within the salt and the lower pressure in the borehole. Similarly, the lithostatic pressure of the surrounding salt, augmented by the compressive stresses of heating, causes salt to creep against the waste container. Brandshaug ${ }^{3}$ predicts that, within a few years after emplacement of a high-level waste container, creep closure of the salt will result in consolidated salt completely enclosing the waste container.

After the consolidation of salt around the waste package, neglecting the consumption of brine by container corrosion, brine in grain boundaries near the waste package can only migrate outward into the surrounding salt. under the influence of pressure graüients caused by transient heating of the salt. Hot salt near the waste packag: expands against the waste package and surrounding salt, creating high compressive stresses near the waste package and resulting in pressure above the lithostatic pressure. Brine pressure further increases because grain-boundary brinc expands more than does the salt and this increased pressure gradicnt caluses brine to flow outward into the cooler salt. ${ }^{4}$ Outward flow of brine relieves the paessure gradiene on the fluit, which firally relaxes to near-lithostatic pressure. If the waste containers are failed by corrosion or crarking, this outward brine movement can become a mechanism for radionuclide transport. 'To determime' 
the extent to which advection by brine in grain boundaries is an important transport mechanism for released radionuclides, it is necessary to estimate the time-dependent migration of brine after salt consolidation.

The formulation of brine movenent with salt as a thermoelastic porous medium, in the context of the cont inuum theory of mixtures, was first published by McTigue. ${ }^{2}$ Chanbre obtained the analytic solutions presented below to the governing equations for a spherical-equivalent waste form and to the coupled radionuclide transport problem. driven by thermoelastic effects. Elsewhere we have presented nanerical results ohtained from this theory. ${ }^{5,6}$ In this report we show the mathematical details and discuss the results predicted hy $1:$ is analysis.

\section{Analysis}

In this report we deal with pressure-driven flow, and we nust first define brine pressure. We definte the relative pore pressure. $P$. of brine as the absolute pore pressure less the undisturbed, far-field pore pressure of brine which is approximated by lithostatic pressure. Consider point $A$ on the wali of a borehole in a repository in salt (Figure 1). Before consolidation, the borehole is open to the atmosphere and the pressure at $A$ is at mospheric, so the relative pressure is a negative quantity. At point $B$, some distance inside the salt, brine in grain boundaries is at a higher pressure. If Darcy's Law is valid for motion of grain-boundary brine. then the higher pressure at $\mathrm{B}$ would drive fluid from B to A. After consolidation, the boundary condition at $A$ will become one of zero mass flux, rather than one of constant pressure. Now pressure gradients in the same regions can result in brine motion back into the salt.

'The Darcy relocity can be written as

$$
v(r, t)=-\frac{k}{\mu} \frac{\partial P}{\partial r}
$$

where $P$ is the relative pore pressure $\left[\mathrm{M} \mathrm{L}^{-1} \mathrm{t}^{-2}\right]$,

$r$ is the distance variable [L],

$k$ is the permeability $\left[\mathrm{L}^{2}\right]$,

$f$ is the fluid riscosity $\left[\mathrm{M} \mathrm{L}^{-1} \mathrm{t}^{-1}\right]$.

To obtain an expression for $\frac{\partial P}{\partial r}$, we treat the salt as a linear thermoelastic solid. Mc'ligue' derived the following expression. written here for salt surrounding an assumed spherical waste solid.

$$
\frac{\partial P}{\partial t}=c \frac{1}{r^{2}} \frac{\partial}{\partial r}\left(r^{2} \frac{\partial P}{\partial r}\right)+b^{\prime} \frac{\partial \theta}{\partial t}, \quad t>0, r>a
$$

where $O(r, t)$ is the relative temperature, artual minus ambient [" 1$]$,

(1) is tire radius of spherical-equivalent waste package [L], and

b'. are constalts which are functions of material properties

$$
\partial^{\prime}=\frac{4 C B\left(1+\nu_{u}\right)}{G\left(1-\nu_{u}\right)}\left[\alpha_{s}^{\prime}+\frac{B(1-\nu)\left(1+\nu_{u}\right)}{2\left(\nu_{u}-\nu^{\prime}\right)} \phi_{0}\left(\alpha_{j}-\alpha_{s}^{\prime \prime}\right)\right]
$$




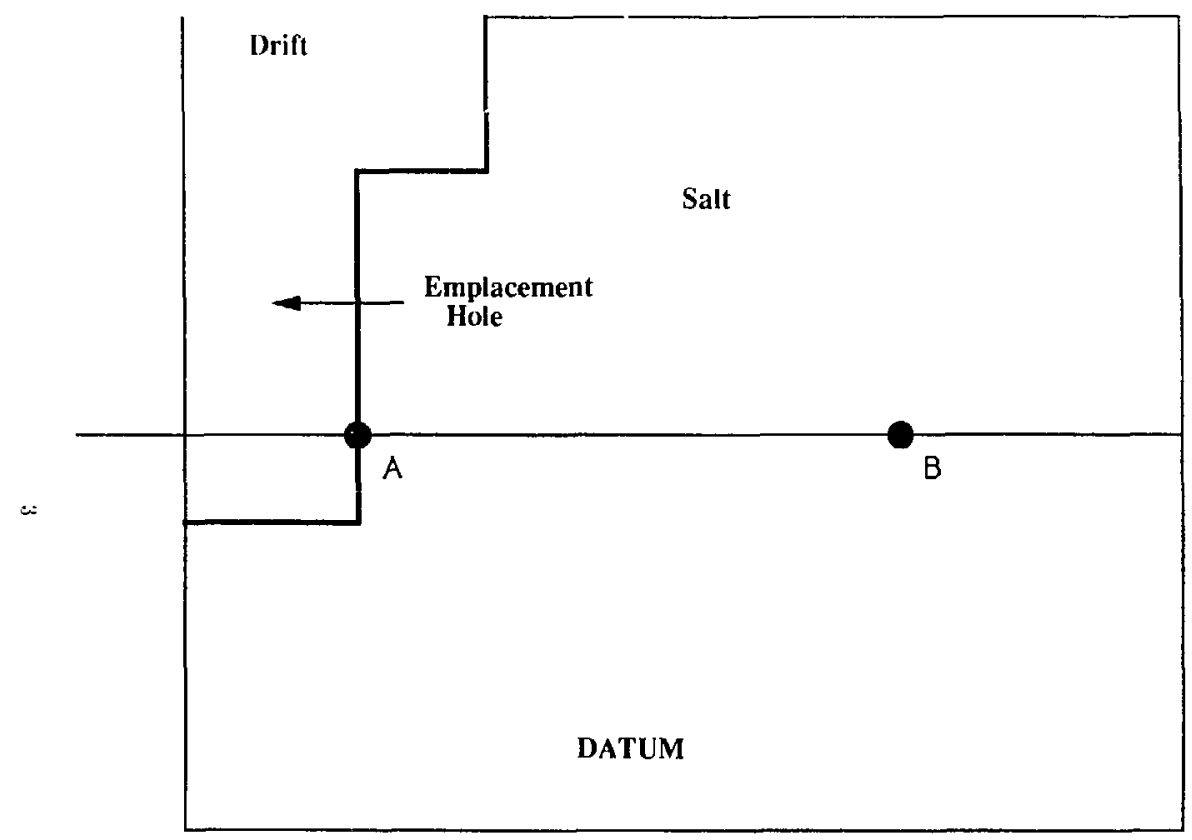

Figure 1. Elevation Schematic, Open Borehole 


$$
c=\frac{k}{\nu} \frac{2 G(1-\nu)}{1-2 \nu}\left[\frac{B^{2}\left(1-2 \nu^{\prime}\right)\left(1+\nu_{u}\right)^{2}}{9(1-\nu)\left(\nu_{u}-\nu\right)}\right]
$$

where $\left(i\right.$ is the shear modulus $\left[\mathrm{M} \mathrm{L}^{-1} \mathrm{t}^{-2}\right.$ ]

$\nu$ is Poisson's ratio for the solid phase

$\nu_{u}$ is the undrained Poisson's ratio

$O_{0}$ is the reference porosity

$a_{J}$ is the fluid-phase thermal expansion coefficient $\left[\mathrm{T}^{-1}\right]$

$\alpha_{s}^{\prime \prime}$ is the second cubical thermal expansion coefficient of the solid $\left[\mathrm{T}^{-1}\right]$, and

$B$ is the pore-pressure modulus, where

$$
\frac{1}{B}=1+\phi_{0} \frac{K\left(1-K_{j} ! h_{s}^{\prime \prime}\right)}{K_{J}\left(1-K_{j} / h_{s}^{\prime \prime}\right)}
$$

in which $K^{*}$ is the bulk modulus $\left[\mathrm{M} \mathrm{L}^{-1} \mathrm{t}^{-2}\right]$, and

the subscripts $f$ and $s$ refer to the fluid phase and soljd phase, respectively.

Equation (:.) states that the variation in pore pressure is due primarily to the change of relative temperature. The derivation of (2) is given in McTigue ${ }^{2}$ and not repeated here. The major assumptions in the derivation are

- The system is linearized.

- Thermal convection is neglected.

- Material properties are constant with temperature. Thus (2) is only valid for small temperature changes.

- The porous material is homogenous.

We present first the derivation of the temperature history around a waste package and then the solution to the above equations for two cases.

\subsection{Temperature Field}

According to (2). the pressure field response is due primarily to the change of temperature, on the right hand-side of (2). In this section we obtain an analytic expression for the time derivative of temperature.

The governing equation for the temperature profile is

$$
\frac{\partial \theta}{\partial t}-\frac{\kappa}{r^{2}} \frac{\partial}{\partial r}\left(r^{2} \frac{\partial \theta}{\partial r}\right)=0, \quad r>a, \iota>0
$$

where $\kappa$ is the thermal diffusivity $\left[\mathrm{L}^{2} / \mathrm{T}\right]$.

Wi use a known thermal decay rate as a boundary condition for solving (3)

$$
-\left.\lambda \frac{\partial \theta}{\partial r}\right|_{r=a}=Q_{0} f(t)
$$


where

$\lambda$ is the thermal conductivity $\left[M \mathrm{~L} \mathrm{t}^{-3} \mathrm{~T}^{-1}\right.$ ],

$Q_{0}$ is the initial heat flux of the waste package $\left[\mathrm{M} / \mathrm{t}^{3}\right]$, and

$f(t)$ is a known time history of the normalized heat flux of the waste package.

The other side conditions are

$$
\begin{array}{ll}
\theta(\infty, t)=0, & t>0 \\
\theta(r, 0)=0, & r>a
\end{array}
$$

To solve (3), (4). (5) and (6) let

$$
V(r, t)=r \theta(r, t)
$$

and substitule into (3)

$$
\frac{\partial V}{\partial t}-\kappa \frac{\partial^{2} V}{\partial r^{2}}=0, \quad r>a, t>0
$$

Taking the Iaplace transform of (8)

$$
s \tilde{V}(\boldsymbol{r}, s)-\kappa \frac{\partial^{2} \tilde{V}}{\partial \boldsymbol{r}^{2}}=0, \quad \mathbf{r}>a
$$

and using (5) oblain

$$
\tilde{V}(r, s)=A_{1} \exp \left\{-\sqrt{\frac{s}{\kappa}} r\right\}
$$

Taking the Laplace transform of (4) we get

$$
\left.\left(-\frac{\partial \bar{V}}{r}+\frac{\bar{V}}{r}\right)\right|_{r=a}=0_{0} \tilde{f}(s)
$$

where

$$
\theta_{0}=\frac{Q_{0} a}{\lambda}
$$

Applying the Laplace Transform of (6) and (11) to (10) we get

$$
A_{1} \sqrt{\frac{s}{\kappa}} \exp \left\{-\sqrt{\frac{s}{\kappa} a}\right\}+\frac{1}{a} \cdot A_{1} \exp \left\{-\sqrt{\frac{\varepsilon}{\kappa}} a\right\}=\theta_{0} f(s)
$$

$A$ : is evaluated to be

$$
A_{1}=\frac{\theta_{0} \tilde{f}(s)}{\sqrt{\frac{s}{\kappa}}+\frac{1}{a}} \exp \left\{\sqrt{\frac{s}{\kappa}} a\right\}
$$

and

$$
\bar{V}=\frac{\theta_{0} \sqrt{\kappa}}{\sqrt{s}+\sqrt{\alpha}} f(s) \exp \left\{-\sqrt{\frac{s}{\kappa}(r-a)}\right\}
$$


where $\alpha=\kappa / a^{2}$. Using the inverse Laplace transform ${ }^{7}$

$$
L^{-1}\left[\frac{\exp \{-\sqrt{\alpha s}\}}{\sqrt{s}+\sqrt{\alpha}} \tilde{f}(s)\right]=\int_{\rho}^{t}\left[\frac{1}{\sqrt{\pi \tau}} \exp \left\{\frac{-\varrho}{4 \tau}\right\}-\sqrt{\alpha} \exp \{\sqrt{\alpha \varrho}+\alpha \tau\} \operatorname{erfc}\left\{\frac{1}{2} \sqrt{\frac{\varrho}{\tau}}+\sqrt{a \tau}\right\}\right] f(t-\tau) d \tau
$$

where

$$
\varrho=\frac{(r-a)^{2}}{\kappa}
$$

in (15) we obcain the salt temperature profile

$$
\begin{aligned}
\theta & =\frac{V(r, t)}{r} \\
& =\frac{\theta_{0} \sqrt{\kappa}}{r} \int_{0}^{t} f(t-\tau)\left[-\frac{1}{\sqrt{\pi \tau}} \exp \left\{\frac{-(r-a)^{2}}{4 \kappa \tau}\right\}-\sqrt{\frac{\kappa}{a^{2}}} \exp \left\{\frac{(r-a)}{a}+\frac{\kappa \tau}{a^{2}}\right\} \operatorname{erfc}\left\{\frac{1}{2} \frac{\tau-a}{\sqrt{\kappa \tau}}+\sqrt{\frac{\kappa \tau}{a^{2}}}\right\}\right] d \tau
\end{aligned}
$$

and the relative temperature at the waste package surface can be evaluated by

$$
\left.\theta\right|_{r=a}=\frac{\theta_{0} \kappa}{a^{2}} \int_{0}^{t} f(t-\tau)\left[\sqrt{\frac{a^{2}}{\pi \kappa \tau}}-\exp \left\{\frac{\kappa \tau}{a^{2}}\right\} \operatorname{erfc}\left\{\sqrt{\frac{\kappa \tau}{a^{2}}}\right\}\right] d \tau
$$

When given a time-history of heat flux from a waste package, (19) allows us to obtain the temperature at the waste package surface and the time derivative of (18) gives us the source term for (2).

We use different initial and boundary conditions for the pore pressure to solve two different cases.

\subsection{Case 1: Open Borehole}

In this case the borehole or the emplacement room or drift is assumed to stay open for the duration of the analysis. The initial condition

$$
P(r, 0)=0, \quad r>a
$$

and the boundary conditions

$$
P(a, t)=-p_{o} \quad t>0
$$

where $p_{o}=$ lithostatic pressure minus atmospheric pressure

$$
\lim _{r \rightarrow \infty} P(r, t)=0 \quad t>0
$$

form the sufficient set. to solve (2).

Let

$$
W(r, l)=r P(r, t)
$$


and substitute into (2), (20), (21) and (22) resulting in

$$
\begin{gathered}
\frac{\partial W}{\partial t}-c \frac{\partial^{2} W^{\prime}}{\partial r^{2}}=b^{\prime} r \frac{\partial \theta(r, t)}{\partial t} \\
W(r, 0)=0 \\
W(a, t)=-a p_{\circ} \\
\lim _{r \rightarrow \infty} \frac{W(r, t)}{r}=0
\end{gathered}
$$

Taking the Laplace transform of (24) we have

$$
s \tilde{W}(r, s)-W(r, 0)=c \frac{\partial^{2} \tilde{W}}{\partial r^{2}}+b^{\prime} r(s \tilde{\theta}(r, s)-\theta(r, 0))
$$

Using (25), (26), (28) and the Laplace Transform of (18) and (27) we have

$$
W(r, s)=A_{2} \exp \left\{-\sqrt{\frac{s}{c} r}\right\}+\frac{b^{\prime} \theta_{o} \sqrt{\kappa}}{\left(1-R^{2}\right)(\sqrt{s}+\sqrt{\alpha})} \tilde{f}(s) \exp \left\{-\sqrt{\frac{s}{\kappa}}(r-a)\right\}
$$

where

$$
R^{2}=c / \kappa
$$

Taking the Laplace transform of (26) and evaluating (29) at $r=a$, we get

$$
\tilde{W}(a, s)=A_{2} \exp \left\{-\sqrt{\frac{s}{c}} a\right\}+\frac{\ell^{\prime} \theta_{0} \sqrt{\kappa}}{\left(1-R^{2}\right)(\sqrt{s}+\sqrt{\alpha})} \tilde{f}(s)=-\frac{a p_{0}}{s}
$$

and the constant $A_{2}$ can be evaluated as

$$
A_{2}=-\frac{a p_{0}}{s} \exp \left\{\sqrt{\frac{s}{c} a}\right\}-\frac{b^{\prime} \theta_{0} \sqrt{\kappa}}{\left(1-R^{2}\right)(\sqrt{ } s} \neg-\frac{}{\sqrt{\alpha})} \tilde{f}(s) \exp \left\{\sqrt{\frac{s}{c} a}\right\}
$$

Then the solution by taking the inverse Laplace transform is

$$
P(r, t)=-\frac{p_{0}}{r / a} \operatorname{erfc}\left\{\frac{r / a-1}{2 R \sqrt{\alpha t}}\right\}+\frac{r b^{\prime} \theta_{0} \sqrt{\kappa}}{\left(1-R^{2}\right)} \int_{0}^{t} f(t-\tau) \Upsilon(r, \tau) d \tau
$$

where

$$
\begin{aligned}
\Upsilon(r, t)= & \frac{1}{\sqrt{\pi t}}\left[\exp \left\{\frac{-\left(\frac{r}{a}-1\right)^{2}}{4 a t}\right\}-\exp \left\{\frac{-\left(\frac{r}{a}-1\right)^{2}}{4 R^{2} \alpha t}\right\}\right] \\
& -\sqrt{a}\left[\exp \left\{\left(\frac{r}{a}-1\right)+\alpha t\right\} \operatorname{erfc}\left\{\frac{\frac{r}{a}-1}{2 \sqrt{\alpha t}}+\sqrt{\alpha t}\right\}-\exp \left\{\frac{\frac{r}{a}-1}{R}+\alpha t\right\} \operatorname{er}\left[\mathrm{c}\left\{\frac{\frac{r}{a}-1}{2 R \sqrt{a t}}+\sqrt{\alpha t}\right\}\right]\right.
\end{aligned}
$$


Using the differentiated form of $(33)$ in (1) we obtain the Darcy velocity at the surface of a sphetical waste package

$$
v(a, t)=-\frac{k p_{0}}{\mu}\left[\frac{1}{\sqrt{\pi R^{2} \kappa t}}+\frac{1}{a}\right]-\frac{k b^{\prime} \theta_{0}}{a \mu(1+R) R}\left\{f(0) e^{\alpha t} \mathrm{e} f \mathrm{fc} \sqrt{\alpha t}+\int_{0}^{t} f^{\prime}(\tau)(1-u(t-\tau)) d \tau\right\}
$$

where

$$
u(t)=1-e^{a t} \operatorname{erfc} \sqrt{a t}
$$

The cumulative brine flow $Q\left[\mathrm{~L}^{3}\right]$ through the waste sphere/salt interface can be calculated with

$$
Q(t)=4 \pi a^{2} \int_{0}^{t} v(a, \tau) d \tau
$$

\subsection{Case 2: Consulldated Salt}

In this case salt creep closes the air gap between the waste package and the rocl salt, in a matter of days to months after the emplacement of the waste package. ${ }^{7}$ Thereafter, neglecting the consumption of brine by container corrosion, brine in grain boundaries faces an impermeable boundary where an air gap had existed in Case 1, and thus brine near the waste package can only migrate outward inio the surrounding salt, under the influence of pressure gradients caused by transient heating of the salt. Hot salt near the waste package expands against the waste package and surtounding salt, restlting in bigh compressive stresses near the waste package. Grain-boundary brine expands more than does the salt and further increases the lacal presssure and pressure gradients that cause brine to flow outward into the cooler salt. Such outward fow of brine relieves the pressure gradient on the fluid, which finally relaxes to near-lithostatic pressure.

The governing equation (2) and the initial condition (20) remain the same. The boundary conditions are now

$$
\begin{array}{rl}
\lim _{r \rightarrow \infty} P(r, t)=0 & t>0 \\
\left.\frac{\partial P(a, t)}{\partial r}\right|_{r=a}=0, & t>0
\end{array}
$$

This set of initial and boundary conditions differs from the set for the open borehole case by the replacement of (21) with (39).

To solve this set of equations first set

$$
W(r, t)=r P(r, t)
$$

and substitute into (2) resulting in

$$
\frac{\partial W}{\partial t}=c \frac{\partial^{2} W}{\partial r^{2}}+b^{\prime} r \frac{\partial \rho(r, t)}{\partial t}, \quad t>0, r>a
$$


Taking the Laplace transform of (41)

$$
s \bar{W}(r, s)-W(r, 0)-c \frac{\partial^{2} \tilde{W}}{\partial r^{2}}=b^{\prime} r(s \bar{\theta}(r, s)-\theta(r, 0))
$$

From the side conditions (20) and the initial condition (6) of the temperature problem and using (15) with the Laplace Transform of (7) in (42) we have

$$
\tilde{W}(r, s)-\frac{c}{s} \frac{\partial^{2} \dot{W}}{\partial r^{2}}=b^{\prime} \frac{\theta_{o} \sqrt{\kappa}}{\sqrt{s}+\sqrt{\alpha}} \tilde{f}(s) \exp \left\{-\sqrt{\frac{s}{\kappa}}(r-a)\right\}
$$

Using the side ccrdition (38), the homogeneous solution to (43) is

$$
\tilde{W}_{h}=A_{3} \exp \left\{-\sqrt{\frac{s}{c} r}\right\}
$$

and the farticular solution is

$$
\bar{W}_{p}=\frac{b^{\prime} \theta_{a}}{\left(1-R^{2}\right)\left(q_{1}+1 / a\right)} \bar{f}(s) \exp \left\{-\sqrt{\frac{s}{\kappa}}(r-a)\right\}
$$

where $q_{1}=\sqrt{s / \kappa}$

Combining the homogeneous and parisicular solutions

$$
\tilde{W}(r, s)=A_{3} \exp \left\{-\sqrt{\frac{s}{c} r}\right\}+\frac{b^{\prime} \theta_{0}}{\left(1-R^{2}\right)\left(g_{1}+1 / a\right)} \tilde{f}(s) \exp \left\{-\sqrt{\frac{s}{\kappa}}(r-a)\right\}
$$

We use (39) to evaluats the constant $A_{3}$

$$
\left.\frac{\partial P}{\partial r}\right|_{r=a}=\left.\frac{\partial \frac{W}{r}}{\partial r}\right|_{r=a}=\left.\frac{1}{a} \frac{\partial W}{\partial r}\right|_{r=a}-\frac{1}{a^{2}} W(a, t)=0
$$

Taking the Lapiace transform of (47)

$$
\left.\frac{1}{a} \frac{\partial \tilde{W}(r, s)}{\partial r}\right|_{r=a}-\frac{1}{a^{2}} \tilde{W}(a, s\}=0
$$

and differentiating (46)

$$
\frac{\partial \tilde{W}(r, s)}{\partial r} \mid=-A_{3} \sqrt{\frac{s}{c}} \exp \left\{-\sqrt{\frac{s}{c} a}\right\}-\frac{b^{\prime} \theta_{0}}{\left(1-R^{2}\right)\left(q_{1}+1 / a\right)} \sqrt{\frac{s}{\kappa}} \tilde{f}(s)
$$

Multiplying both sides of (48) by $a^{2}$ and substituting (49) and (46) into (48), we can evaluate $A_{3}$

$$
-a A_{3} \sqrt{\frac{s}{c}} \exp \left\{-\sqrt{\frac{s}{c} a}\right\}-\frac{b^{\prime} \theta_{\mathrm{a}} a}{\left(1-R^{2}\right)\left(q_{1}+1 / a\right)} \sqrt{\frac{s}{\kappa}} \tilde{f}(s)-A_{3} \exp \left\{-\sqrt{v} \sqrt{\frac{s}{c}} a\right\}-\frac{b^{\prime} \theta_{\mathrm{a}}}{\left(1-R^{2}\right)\left(q_{1}+1 / a\right)} \tilde{f}(s)=0
$$




$$
A_{3}=\frac{-b^{\prime} \theta_{0}}{(1 / a+\sqrt{s / c})\left(1-R^{2}\right)} \tilde{f}(s) \exp \left\{V^{i} \frac{\sqrt{s}}{\kappa} \frac{a}{R}\right\}
$$

Then

$$
\hat{W}(r, s)=\frac{b^{\prime} \theta_{0}}{\left(1-R^{2}\right)\left(\sqrt{\frac{s}{\alpha}}+\frac{1}{a}\right)} \tilde{f}(s) \exp \left\{-\sqrt{\left.\frac{s}{i}(r-a)\right\}-\frac{b^{\prime} \theta_{0}}{\left(1-R^{2}\right)\left(\sqrt{\frac{s}{c}}+\frac{1}{a}\right)}} \tilde{f}(s) \exp \left\{-\frac{\sqrt{\frac{s}{\alpha}}}{R}(r-a)\right\}\right.
$$

(52) can be written as

$$
\dot{F}(r, s)=\delta \frac{\tilde{f}(s)}{\sqrt{s}+\sqrt{\alpha}} \exp \{-\sqrt{\beta s}\}-R \delta \frac{\tilde{f}(s)}{\sqrt{s}+\sqrt{w}} \exp \{-\sqrt{\gamma s}\}
$$

where

$$
\begin{aligned}
\delta=\frac{b^{\prime} \sqrt{\kappa} \theta_{0}}{1-R^{2}}, & \beta=\frac{(r / a-1)^{2}}{\alpha} \\
w=\frac{c}{a^{2}}=\alpha R^{2}, & \gamma=\frac{(r / a-1)^{2}}{\alpha R^{2}}
\end{aligned}
$$

L'sing the inverse Laplace transform ${ }^{7}$

$$
L^{-1}\left[\frac{1}{\sqrt{s}+\sqrt{\alpha}} \exp \{-\sqrt{\beta s}\}\right]=\frac{1}{\sqrt{\pi t}} \exp \left\{\frac{-\beta}{4 t}\right\}-\sqrt{\alpha} \exp \{\sqrt{\alpha \beta}+\alpha t\} \operatorname{erfc}\left\{\frac{1}{2} \sqrt{\frac{\beta}{t}}+\sqrt{\alpha t}\right\}
$$

and the convolution theorem we can obtain the solution for $W$

$$
\begin{aligned}
& W(r . t)=\delta \int_{0}^{t} f(t-\tau)\left[\frac{1}{\sqrt{\pi \tau}} \exp \left\{\frac{-(r / a-1)^{2}}{4 \alpha \tau}\right\}-\sqrt{\alpha} \exp \{(r / a-1)+\alpha \tau\} \operatorname{erfc}\left\{\frac{r / a-1}{2 \sqrt{\alpha \tau}}+\sqrt{\alpha \tau}\right\}\right] d \tau \\
& -\delta R \int_{0}^{t} f(t-\tau)\left[\frac{1}{\sqrt{\pi \tau}} \exp \left\{\frac{-(r / a-1)^{2}}{4 \alpha R^{2} \tau}\right\}-\sqrt{\alpha} R \exp \left\{(r / a-1)+\alpha R^{2} \tau\right\} \operatorname{erfc}\left\{\frac{r / a-1}{2 R \sqrt{\alpha \tau}}+R \sqrt{\alpha \tau}\right\}\right] d \tau
\end{aligned}
$$

The pore pressure is

$$
P(r, t)=\frac{W(r, t)}{r}
$$

and the pore pressure evaluated at the surface of the waste package is

$$
\begin{gathered}
\lim _{r \rightarrow a} P(r, t)=\lim _{r \rightarrow a} \frac{W(r, t)}{r}=\frac{\delta}{a} \int_{0}^{t} f(t-\tau)\left[\frac{1}{\sqrt{\pi \tau}}-\sqrt{\alpha} \exp \{\alpha \tau\} \operatorname{erfc}\{\sqrt{\alpha \tau}\}\right] d \tau \\
-\frac{\delta R}{a} \int_{0}^{t} f(t-\tau)\left[\frac{1}{\sqrt{\pi \tau}}-\sqrt{\alpha} R \exp \left\{R^{2} \alpha \tau\right\} \operatorname{erfc}\{R \sqrt{\alpha \tau}\}\right] d \tau
\end{gathered}
$$

With the pressure gradient, we can calculate the pressure-driven brine migration from (1). We first define

$$
\xi=r / a
$$


and write

$$
\imath(\xi, t)=-\frac{k}{\mu} \frac{\partial P}{\partial r}=-\frac{k}{\mu}\left(\frac{1}{r} \frac{\partial W}{\partial r}-\frac{W}{r^{2}}\right)=-\frac{k}{\mu a^{2}}\left(\frac{1}{\xi} \frac{\partial W}{\partial \xi}-\frac{W}{\xi^{2}}\right)
$$

Define

$$
\begin{gathered}
D(\xi, t)=\frac{1}{\sqrt{\pi t}} \exp \left\{\frac{-(\xi-1)^{2}}{4 c t}\right\}-\sqrt{\alpha} \exp \{(\xi-1)+\alpha t\} \operatorname{erfc}\left\{\frac{\xi-1}{2 \sqrt{\alpha t}}+\sqrt{\alpha t}\right\} \\
-R \frac{1}{\sqrt{\pi t}} \exp \left\{\frac{-(\xi-1)^{2}}{4 a R^{2} t}\right\}+\sqrt{\alpha} R^{2} \exp \left\{(\xi-1)+a R^{2} t\right\} \operatorname{erfc}\left\{\frac{\xi-1}{2 R \sqrt{\alpha t}}+R \sqrt{a t}\right\}
\end{gathered}
$$

and the partial gradient of $D$ is

$$
\begin{aligned}
& \frac{\partial \supset(\xi, t)}{\partial \xi}=-\frac{\xi-1}{2 \alpha \sqrt{\pi l^{3}}} \exp \left\{\frac{-(\xi-1)^{2}}{4 \alpha t}\right\}-\sqrt{\alpha} \exp \{(\xi-1)+\alpha t\} \text { e,f }\left\{\frac{\xi-1}{2 \sqrt{\alpha t}}+\sqrt{\alpha t}\right\} \\
& +\frac{1}{\sqrt{\pi t}} \exp \left\{\frac{-(\xi-1)^{2}}{4 \alpha t}\right\}+\frac{\xi-1}{2 \alpha R \sqrt{\pi t^{3}}} \exp \left\{\frac{-(\xi-:)^{2}}{4 \alpha R^{2} t}\right\} \\
& +\sqrt{\alpha} R^{2} \exp \left\{(\xi-1)+\alpha R^{2} t\right\} \operatorname{erfc}\left(\frac{\xi-1}{2 R \sqrt{\alpha t}}+R \sqrt{\alpha t}\right)-\frac{R}{\sqrt{\pi t}} \exp \left\{\frac{-(\xi-1)^{2}}{4 \alpha R^{2} t}\right\}
\end{aligned}
$$

If we now define a $\Psi$ function as in (33) and (34). we have

$$
\begin{gathered}
\Psi(\xi, t)=-\frac{1}{\xi} \frac{\partial D}{\partial \xi}+\frac{D}{\xi^{2}}=\left(1-\frac{1}{\xi}\right) \frac{1}{2 \omega \sqrt{\pi t^{3}}}\left[\exp \left\{\frac{-(\xi-1)^{2}}{4 \alpha t}\right\}-\frac{1}{R} \exp \left\{\frac{\left.-(\xi-1)^{2}\right\}}{4 \alpha R^{2} t}\right)\right] \\
-\frac{1}{\sqrt{\pi t}} \frac{1}{\xi}\left(1-\frac{1}{\xi}\right)\left[\exp \left\{\frac{-(\xi-1)^{2}}{4 \alpha t}\right\}-R \exp \left\{\frac{-(\xi-1)^{2}}{4 \alpha R^{2} t}\right\}\right] \\
+\sqrt{\alpha} \frac{1}{\xi}\left(1-\frac{1}{\xi}\right)\left[\exp \{(\xi-1)+\sigma t\} \operatorname{erfc}\left\{\frac{\xi-1}{2 \sqrt{\alpha t}}+\sqrt{\alpha t}\right\}-R^{2} \exp \left\{(\xi-1)+\alpha R^{2} t\right\} \operatorname{erfc}\left\{\frac{\xi-1}{2 R \sqrt{\alpha t}}+R \sqrt{\alpha t}\right\}\right]
\end{gathered}
$$

Then we write the Darcian brine migration velocity as

$$
v(\xi, t)=\frac{k b^{\prime} \sqrt{\kappa} \theta_{0}}{\mu a^{2}\left(1-R^{2}\right)} \int_{0}^{t} f(t-\tau) \Psi(\xi, \tau) d \tau
$$

Fquation (63) can be used to compute brine flow near a waste package around which salt has fully consolidated.

\section{Numerical Illustration}

lo this section we illustrate the above analy tic solutions using parameters typical of a nuclear waste repositury in salt. Wo use a waste sphere of radius $0.76 \mathrm{~m}$ in an infinite salt bed. 


\subsection{Temperature Profile}

We consider a typical waste package containing spent fuel from pressurized water reactors. ${ }^{\beta}$ This package contains 5.5 metric tons of uranium initially and has a thertual flux $Q_{0}$ of 928 watts per square meter of surface area initally. We approximate the normalized thermal flux, $f(t)$ in $(4)$, using the data in Table 1 , as

$$
f(t)=e^{-0.024 t}+e^{-0.0075 t}+e^{0.0046 t}-e^{0.0068 t}-e^{-0.0073 t}
$$

Table II lists the material properties used in these numerical illustrations. Figure 2 shows che known time history of normalized thermal flux from the reference waste package and the fitted analytic expression.

Table 1. Relative Pou $\cdots$ of a Waste Package Containing Spent Fuel from PWR, 10 years out of reactor

\begin{tabular}{|c|c|}
\hline Years After Emplacement & Relative Power \\
\hline 0 & 1.000 \\
5 & 0.841 \\
10 & 0.750 \\
15 & 0.683 \\
20 & 0.625 \\
30 & 0.524 \\
50 & 0.389 \\
70 & 0.303 \\
100 & 0.240 \\
300 & 0.100 \\
500 & 0.070 \\
800 & 0.050 \\
1000 & 0.045 \\
\hline
\end{tabular}

Source: Reference 8 .

Lsing the $f(t)$ thus obtained, we solve for the temperature field around the waste package as a function of radial distance and time. Figure 3 shows the temperature profile as a function of distance from the surface of the waste package 1 year, 10 years and 100 years after emplacement in salt. Because salt is a relatively good conductor of heat, the rise in temperature over the ambient decays rapidly. The time derivative of the relative temperature serves as the input and driving force for brine migration. Figure 4 shows the time history of relative temperature at the surface of the waste sphere. The rnaximum temperature is reached rapidly, although Figure 2 and 3 show that the thermal perturbation lasts for at least several hurdred years. 


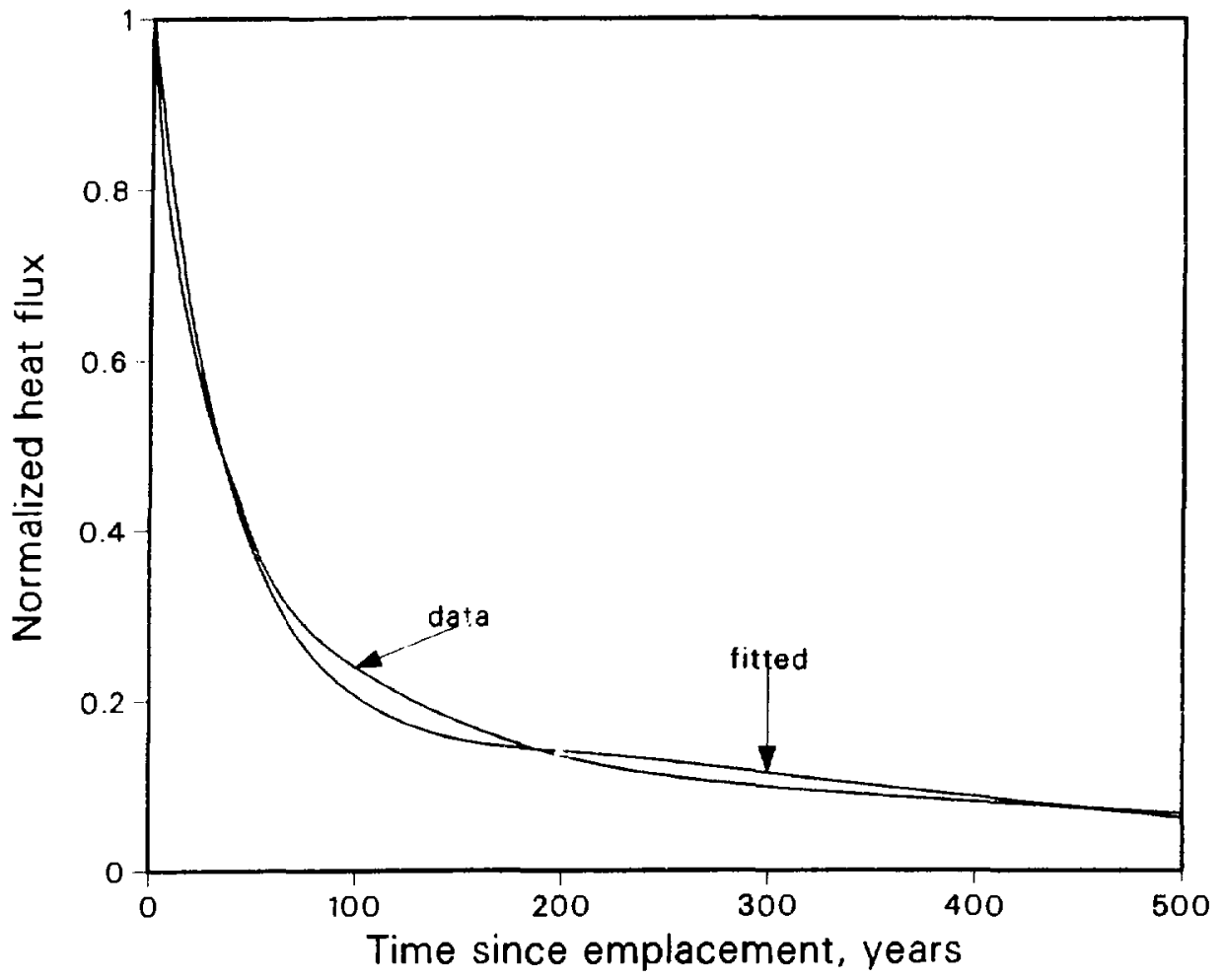

Figure 2. Comparison of Fitted versus Actual Heat Flux 


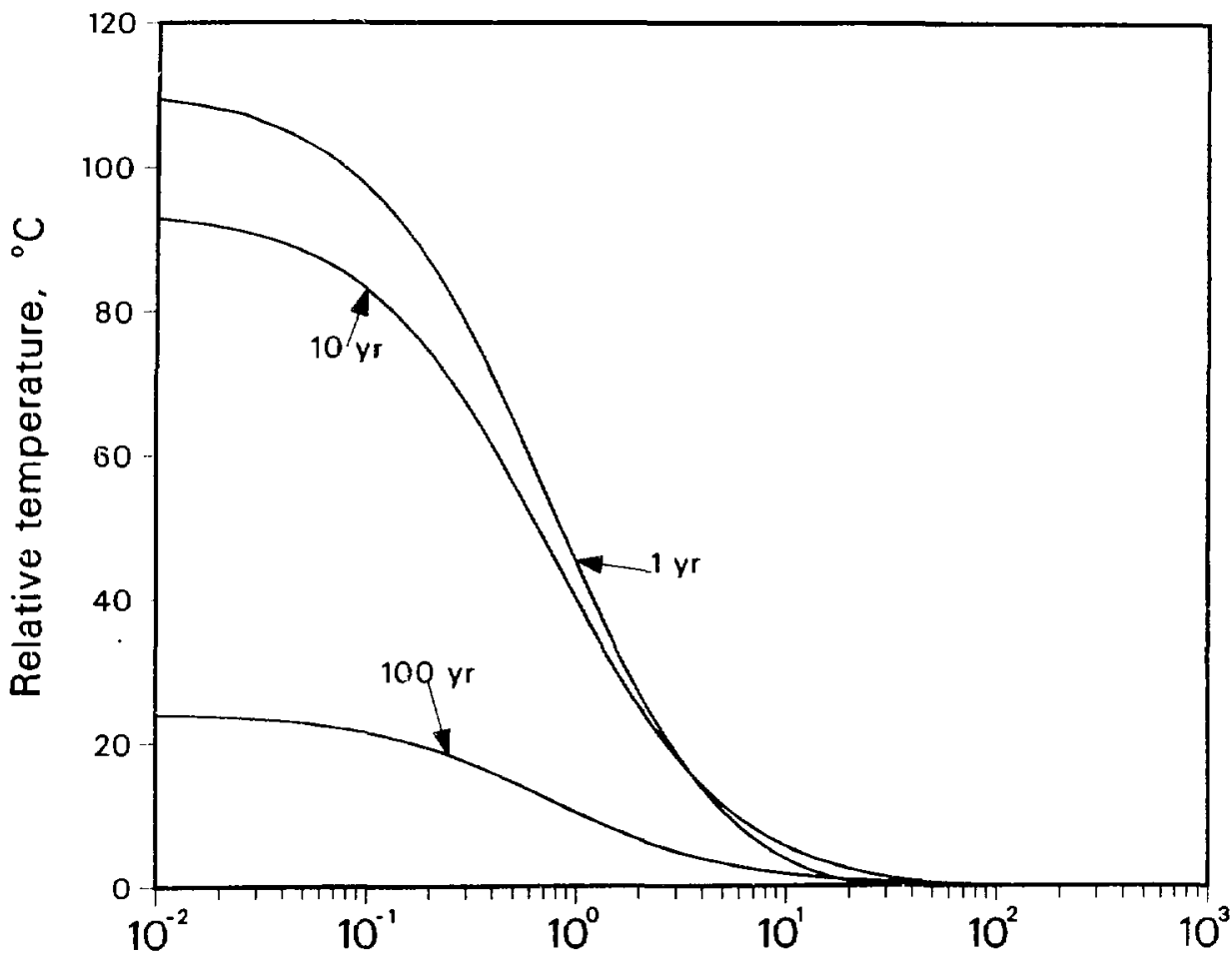

Distance from waste package, meters

Figure 3. Relative Temperature in Salt After Emplacement 


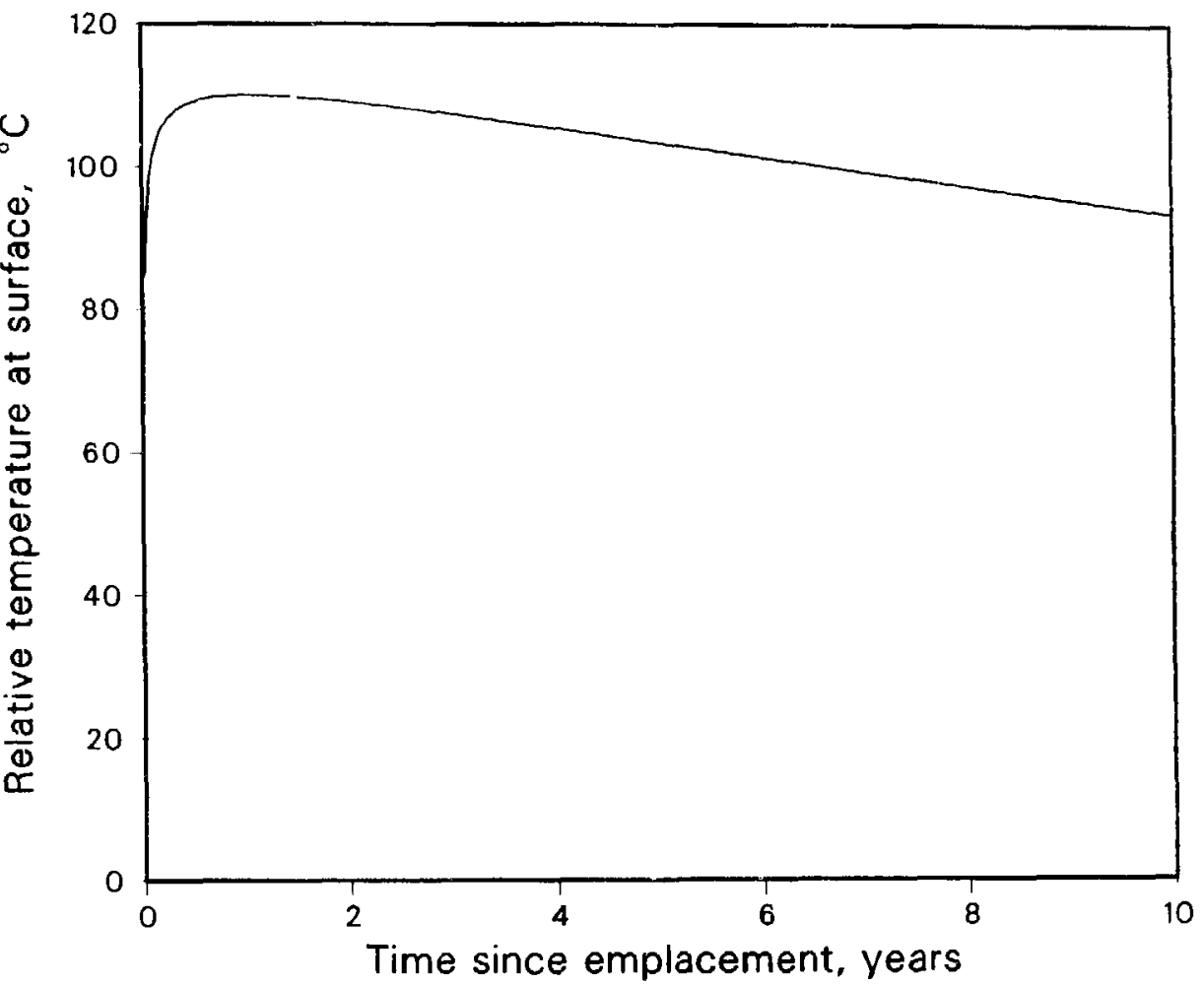

Figure 4. Relative Temperature at Waste Surface After Emplacement 
Table II. Parameter Values Used in Calculations

(After McTigue, ${ }^{2}$ for the Salado Formation, Delaware Basin, New Mexico)

\begin{tabular}{|c|c|c|}
\hline Property & Value & Units \\
\hline $\begin{array}{l}\text { Conductivity }(\lambda) \\
\text { Heat Capacity }\left(\rho c_{v}\right)\end{array}$ & $\begin{array}{c}6.60 \\
1.89 \times 10^{6} \\
\end{array}$ & $\begin{array}{l}N \cdot \mathrm{m}^{-1} \cdot \mathrm{K}^{-1} \\
\mathrm{~J} \cdot \mathrm{m}^{-3} \cdot \mathrm{K}^{-1}\end{array}$ \\
\hline Drained Bulk Modulus ( $K$ ) & 20.7 & $\mathrm{GPa}$ \\
\hline Fluid Bulk Modulus $\left(K_{f}\right)$ & 2.0 & $\mathrm{GPa}$ \\
\hline Solid Bulk Moduli $\left(K_{s}^{\prime}, K_{s}^{\prime \prime}\right)$ & 23.5 & $\mathrm{GPa}$ \\
\hline Shear Modulus ( $G$ ) & 12.4 & $\mathrm{GPa}$ \\
\hline Porosity $\left(\phi_{0}\right)$ & 0.001 & \\
\hline Permeability (k) & $10^{-21}$ & $\mathrm{~m}^{2}$ \\
\hline Fluid Expansivity $\left(\alpha_{J}\right)$ & $3.0 \times 10^{-4}$ & $K^{-1}$ \\
\hline Solid Expansivity $\left(\alpha_{s}^{\prime}, \alpha_{s}^{\prime \prime}\right)$ & $1.2 \times 10^{-4}$ & $K^{-1}$ \\
\hline Fluid Viscosity $(\mu)$ & $1.0 \times 10^{-3}$ & $\mathrm{~Pa} \cdot \mathrm{s}$ \\
\hline$B=\left\{1+\phi_{0} \frac{K\left(1-K_{f} / K^{\prime \prime}\right)}{K_{f}\left(1-K / K^{\prime}\right)}\right\}^{-1}$ & 0.93 & \\
\hline Poisson's Ratio $(\nu)$ & 0.25 & \\
\hline Undrained Poisson's Ratio $\left(v_{u}\right)$ & 0.27 & \\
\hline$b^{\prime}$, Eq. $(2 a)$ & 29.0 & $\mathrm{kPa} \cdot \mathrm{K}^{-1}$ \\
\hline Fluid Diffusivity (c) & $0.16 \times 10^{-6}$ & $\mathrm{~m}^{2} \cdot \mathrm{s}^{-1}$ \\
\hline Thermal Diffusivity $(\kappa)$ & $3.5 \times 10^{-6}$ & $\mathrm{~m}^{2} \cdot \mathrm{s}^{-1}$ \\
\hline$R=\sqrt{c / \kappa}$ & 0.21 & \\
\hline
\end{tabular}

\subsection{Brine Migration into an Open Borchole}

Using the analytic heat flux shown in Figure 2 and material properties of Table II, (35) is used to compute the velocity of brine migration into a borehole that has bees kept open. The results for a spherical-equivalent waste package embedded in an infinite salt medium, using a permeability of $10^{-21} \mathrm{~m}^{2}$, are shown in Figure 5. We assume a far-field brine pressure of lithostatic plus atmospheric $\left(p_{0}+0.1\right)$ of $16.3 \mathrm{MPa}$. It can be seen that the magnitude of brine inflow is small and that steady state is reached rapidly.

In the Environmental Assessments ${ }^{9}$ of candidate salt repository sites, brine migration is predicted from an equation of the form derived for migration of brine inclusions under the influence of a temperature 


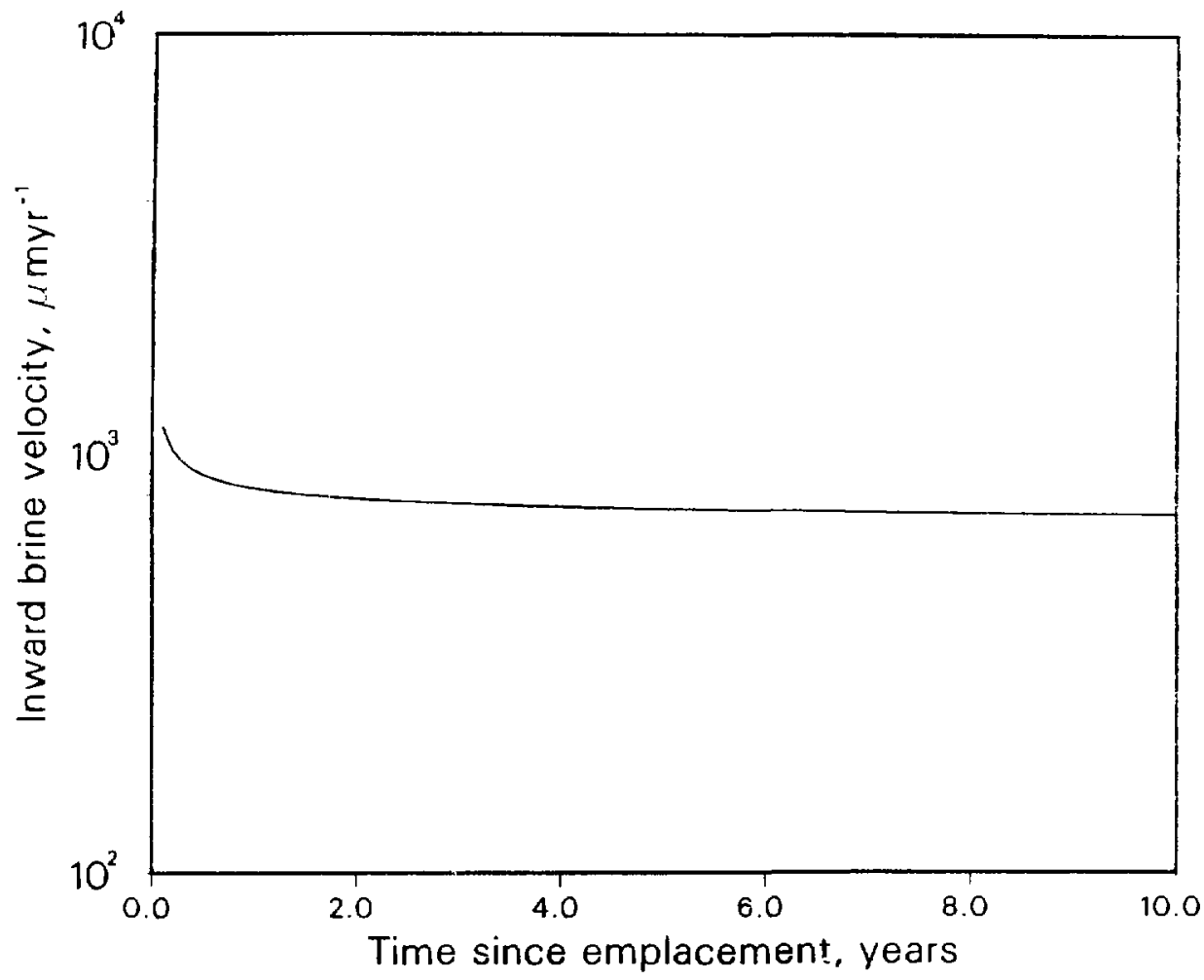

Figure 5. Inward Brine Migration Velocity into an Open Borehole 


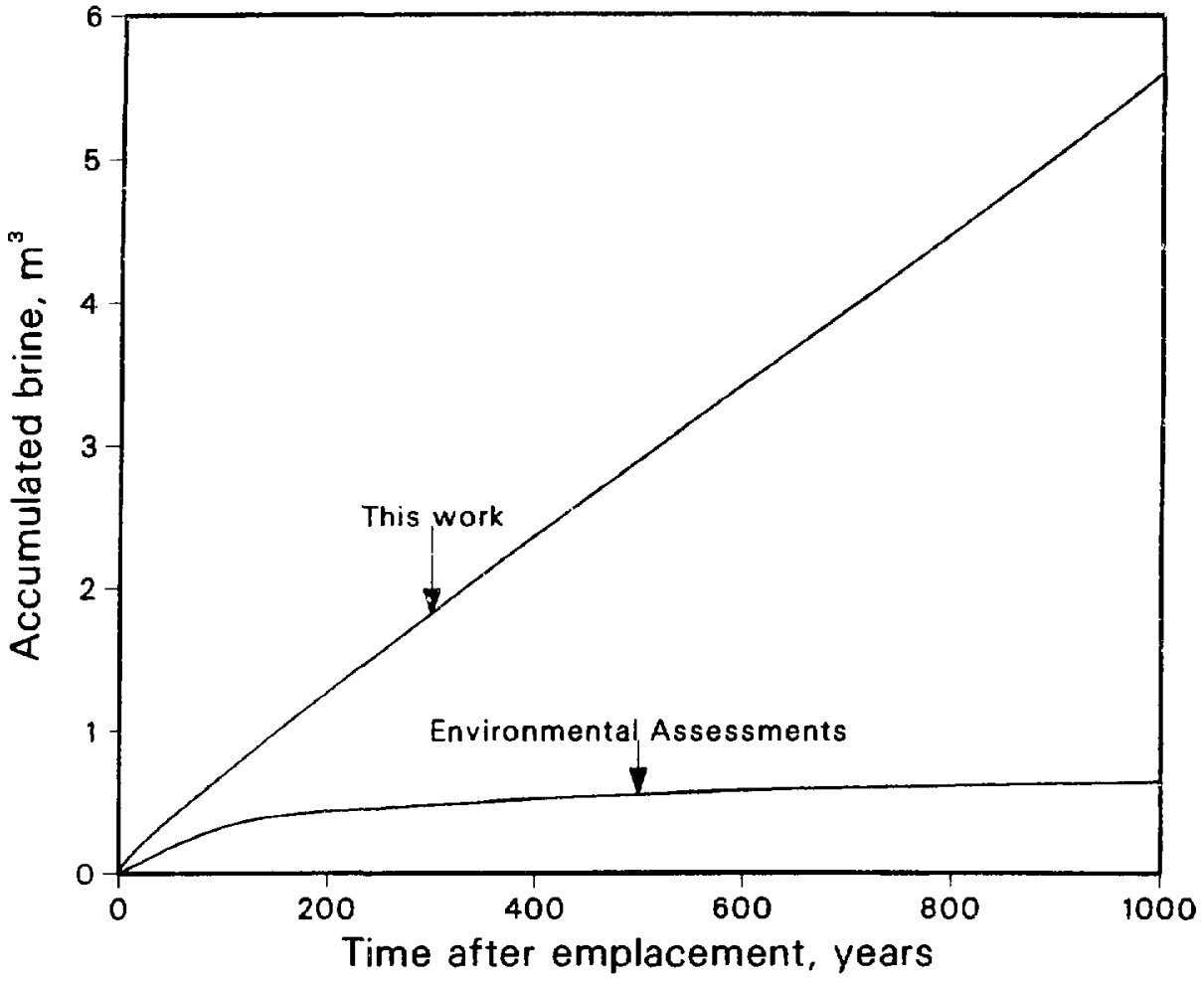

Figure 6 . Brine Flow into an Open Borehole 
gradient. Darcian flow is not included. In Figure 6 the Environmental Assessments prediction of cumulative brine inflow is shown along with our results for pressure-gradient flow, Case 1, Section 2.2. 'The calculated results are unrealistic for times greater than a few years, after which no open borehole is predicled to exist. However, results are calculated to 1000 years for a hypothetical open borehole, to compare with brine inflow calculations appearing in the Environmental Assessments. For the parameter values adopted herein, grainboundary migration into an op n borehole is driven almost entirely by the large difference between pressures in the far field and in the open borehole. For the long time scales of Figure 6, we calculate that brine will accumulate linearly with time. The Environmental Assessments incorrectly predict that brine accumulation is driven entirely by temperature gradients and reaches a constant value after the assurned effects of the thermal pulse have disappeared.

\subsection{Brine Migration in Consolidated Salt}

Equation (63) is used to compute brine migration velocity in salt consolidated around a waste package as a function of radial distance and time. In Figure 7 we plot the local brine pressure, relative to the far-field brine pressure, as a function of radial distance and time. After creep closes the anmular space between the waste package and the emplacement hole wall, the pressure of brine rises above the fa-field pressure because of thermal expansion of the hotter salt and brine. The built-up pressure relieves rapidly as brine flows outwards into cooler salt. In 100 years there is almost no pressure gradient and brine migration has become negligible. In 100 years the brine pressure in the immediate vicinity of the waste package is slightly less than the far-field brine pressure. At these times, brine will move toward the waste package.

Vsing the results shown in Figure 7 and the material properties in Table II, the Darcian brine migration velocity can be calculated. The results for 0.1 year, 1 year and 10 years are shown in Figure 8 . The brine ritigratiun velocities are very low, of the order of microns per year. Brine flow is highly transient and is localized to the few meters of sait near the waste package. The maximum velocity occurs a few meters from the waste package and essentially disappears within ten years. Brine migration back towards the waste package occurs. but the reverse migration is weak and occurs at later time a few meters from the waste package.

'To investigate the sensitivity of our results to uncertainty in material properties, we varied the permeability from $10^{-20} \mathrm{~m}^{2} / \mathrm{a}$ to $10^{-22} \mathrm{~m}^{2} / \mathrm{a}$. The resultant brine migration velocities are shown in Figure 9 . Although the permeability is varied a hundredfold, the peak velocity varies only fourfold.

Other material properties in Table 11 are uncertain and further sensitivity analysis can he done. For example. thermal conductivity is temperature dependent and experimental results al the same temperature varies substantially. The National Bureau of Standards ${ }^{10}$ recommends a value of $6.57 \mathrm{~W} \cdot \mathrm{m}^{-1} \cdot \mathrm{K}^{-1}$ at $300 \mathrm{k}$ and $4.80 \mathrm{~W}^{\prime} \cdot \mathrm{m}^{-1} \cdot \mathrm{K}^{-1}$ at $400 \mathrm{~K}$. 'The elastic properties of sait shown in Table Il are from extensive measurements; 


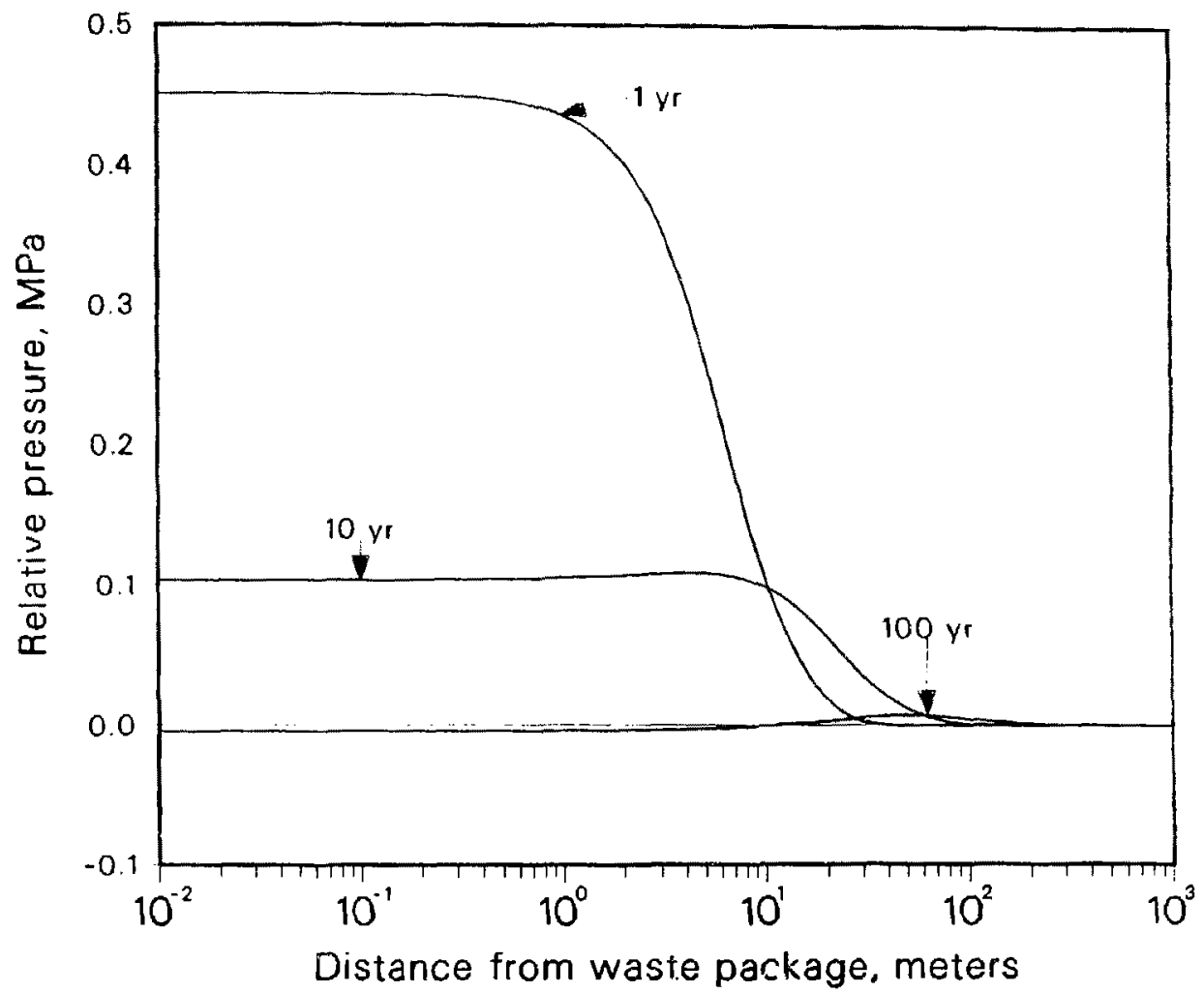

Figure 7. Pressure Profile in: Consolidated Salt 


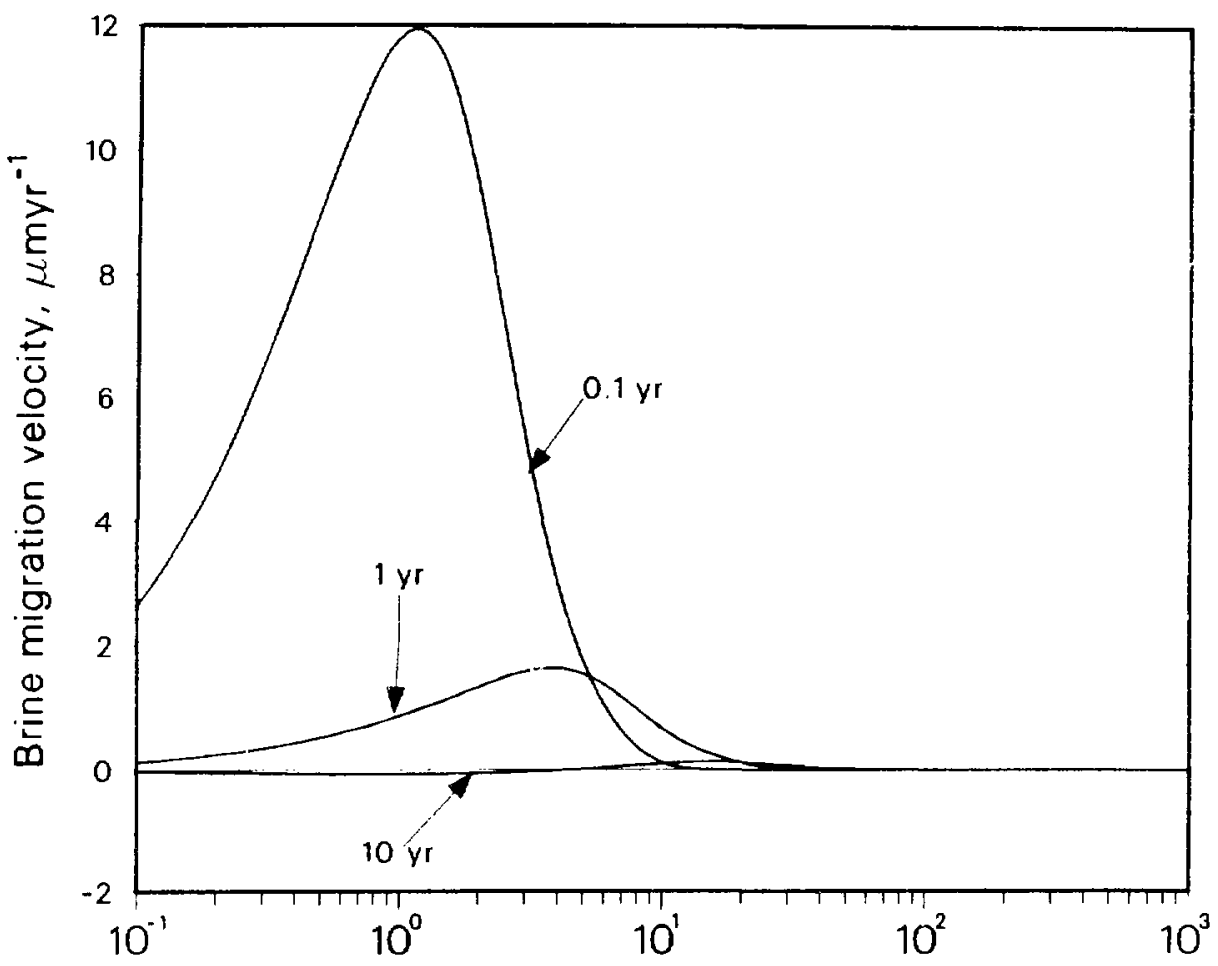

Distance from waste package, meters

Figure 8. Darcian Brine Migration Velocity in Consolidated Salt 


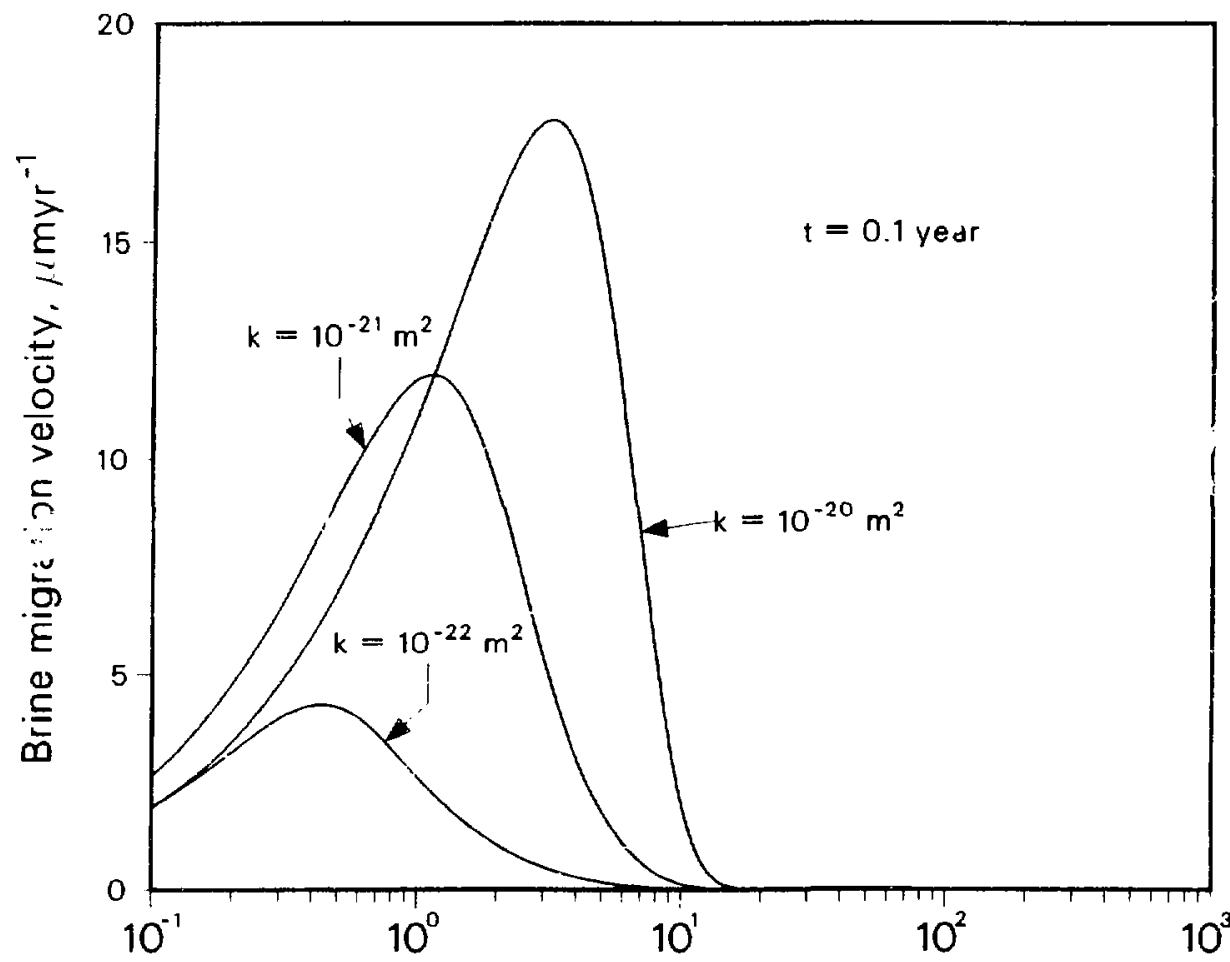

Distance from waste package, meters

Figure 9. Sensitivity of Brine Migration Velocity to Salt Permeability 
of salt properties at the Waste Isolation Pilot Plant and are quite reliable. The viscosity of brine is probably twice that of pure water, or $2 \times 10^{-3} \mathrm{~Pa} \cdot \mathrm{s}$, but is a sharper function of temperature. These variations in parameter values may have offsetting effect on the overall analysis.

\section{Comparison of Advective and Diffusive Radionuclide Transport}

In this section we compare the rate of mass transport by advection with the rate by difusion. ${ }^{11}$ The mass rate of advective transport at Ir sation $r$ from a spherical surface and at time $t$ is given by

$$
\dot{m}_{a}(r, t)=4 \pi \epsilon r^{2} v_{p} N(r, t)
$$

where $\dot{m}_{a}$ is the mass rate of advective transport [M/t],

$\nu_{p}$ is the pore brine migration velocity, $v_{p}=\% / \epsilon[\mathrm{L} / \mathrm{t}]$ from section 3.3 , and

$N(r, t)$ is the species concentration at position $r$ and time $t\left[\mathrm{M} / \mathrm{L}^{3}\right]$.

To obtain an estimate for $N(r, t)$, we use the result from diffusive transport analysis. This assumes that the rate of advective transport by brine migration is small compared to the transport rate by diffusion through the brine.

The mass rate of diffusion is given by

$$
\dot{m}_{d}(r, t)=-4 \pi c r^{2} D \frac{\partial N(r, t)}{\partial r}
$$

where $\dot{m}_{d}$ is the mass rate $f$ diffusion $[M / t]$,

$D$ is the species diffusion coefficient $\left[L^{2} / t\right]$.

For long-lived solubility-limited species the diffusion-controlled concentration is given by

$$
N(r, t)=\frac{N^{*} r_{o}}{r} \operatorname{erfc}\left\{\frac{\left(r-r_{o}\right)}{2} \sqrt{K / D t}\right\}, \quad r>r_{o}, \quad t>0
$$

where $K$ is the species retardation coefficient, and

$N^{*}$ is the solubility of the species $\left[\mathrm{M} / \mathrm{L}^{3}\right]$.

In Figure 10 we show the absolute value of the mass transport rates as predicted by advective brine migration and by molecular diffusion as a function of distance from the waste surface, for 10 years and 100 years. For this comparison we use $\varepsilon=0.001, D=10^{-11} \mathrm{~m}^{2} / \mathrm{s}, N^{*}=10^{-3} \mathrm{~g} / \mathrm{m}^{3}$, and $\hbar=1$. The advective flux at 10 and 100 years are actually negative. Figure 10 shows that for the parameters selected here, the mass transport rate by diffusion is always higher than the mass transport rate by advection.

Figure 11 shows the flux comparison at one year. At one year the advective flux is posifive, but its magniturde is smaller than the diffusive flux.

The above results can be undcrstood through Figure 12 where ve show on a non-dimensionalized basis the concentration profile as predicted by the diffusive analysis and the brine migration velocity, at ten years. 


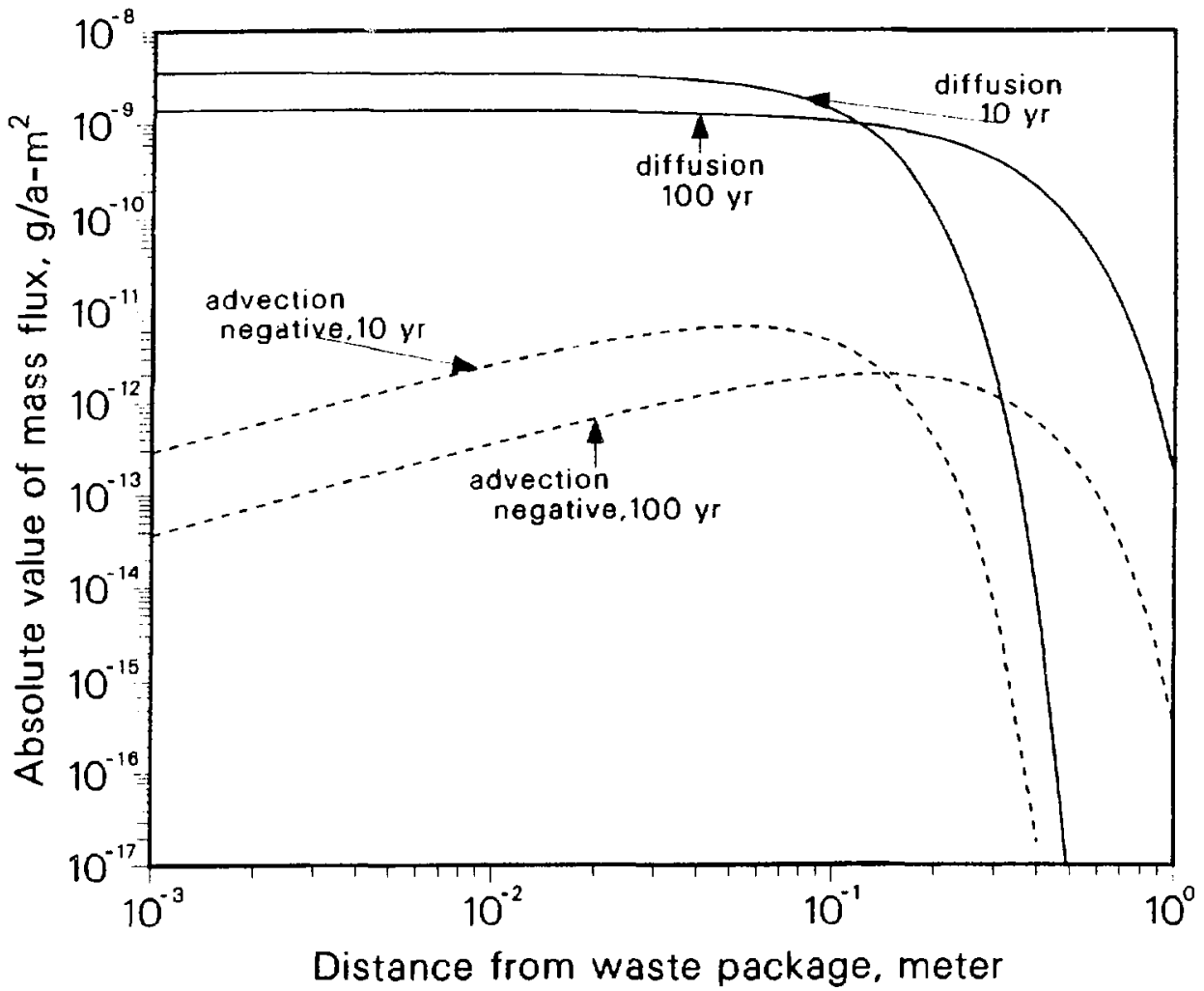

Figure 10. Mass Flux Rate by Advection and Molecular Diffusion 


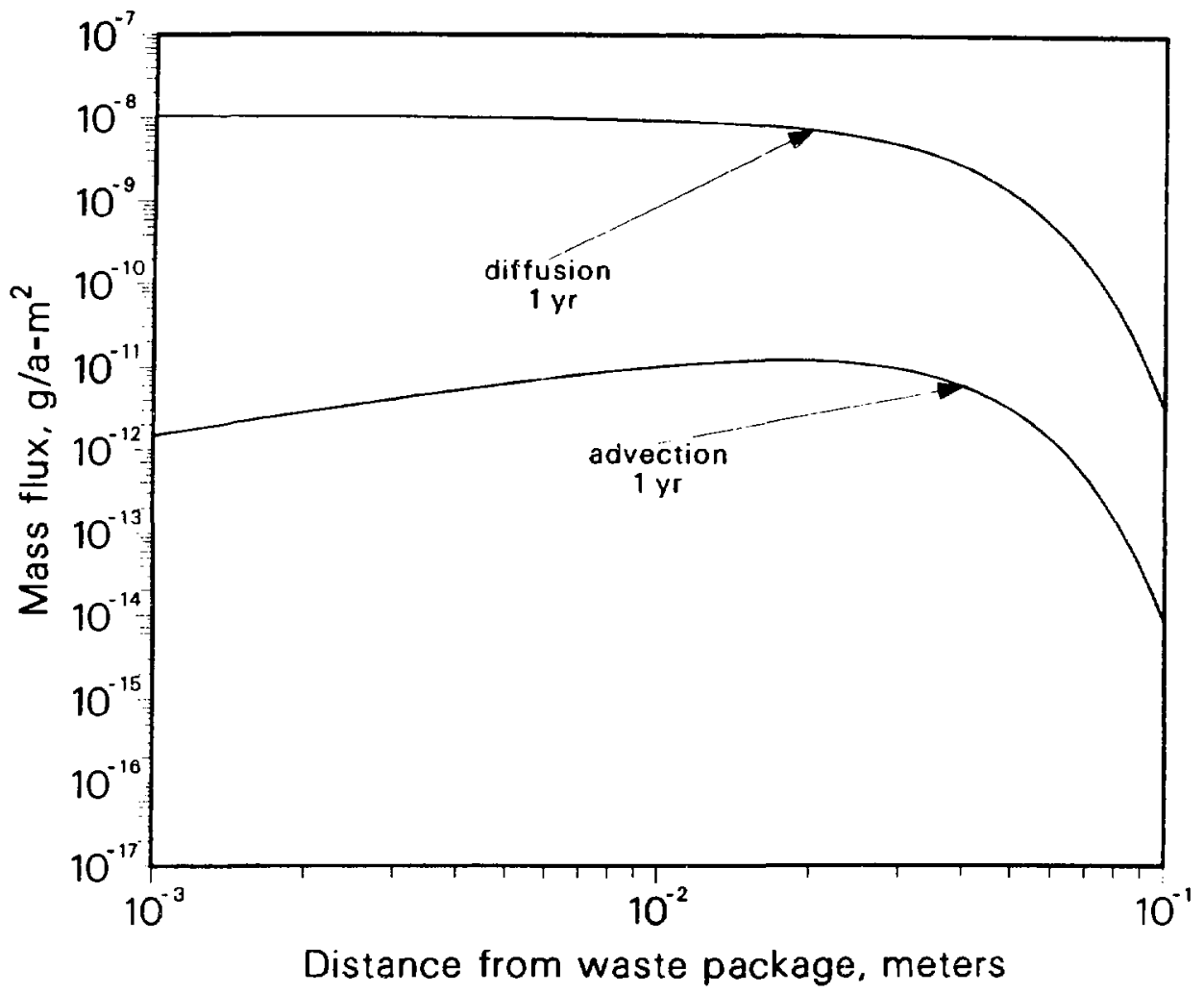

Figure 11. Comparison of Mass Flux Rate at Early Time 


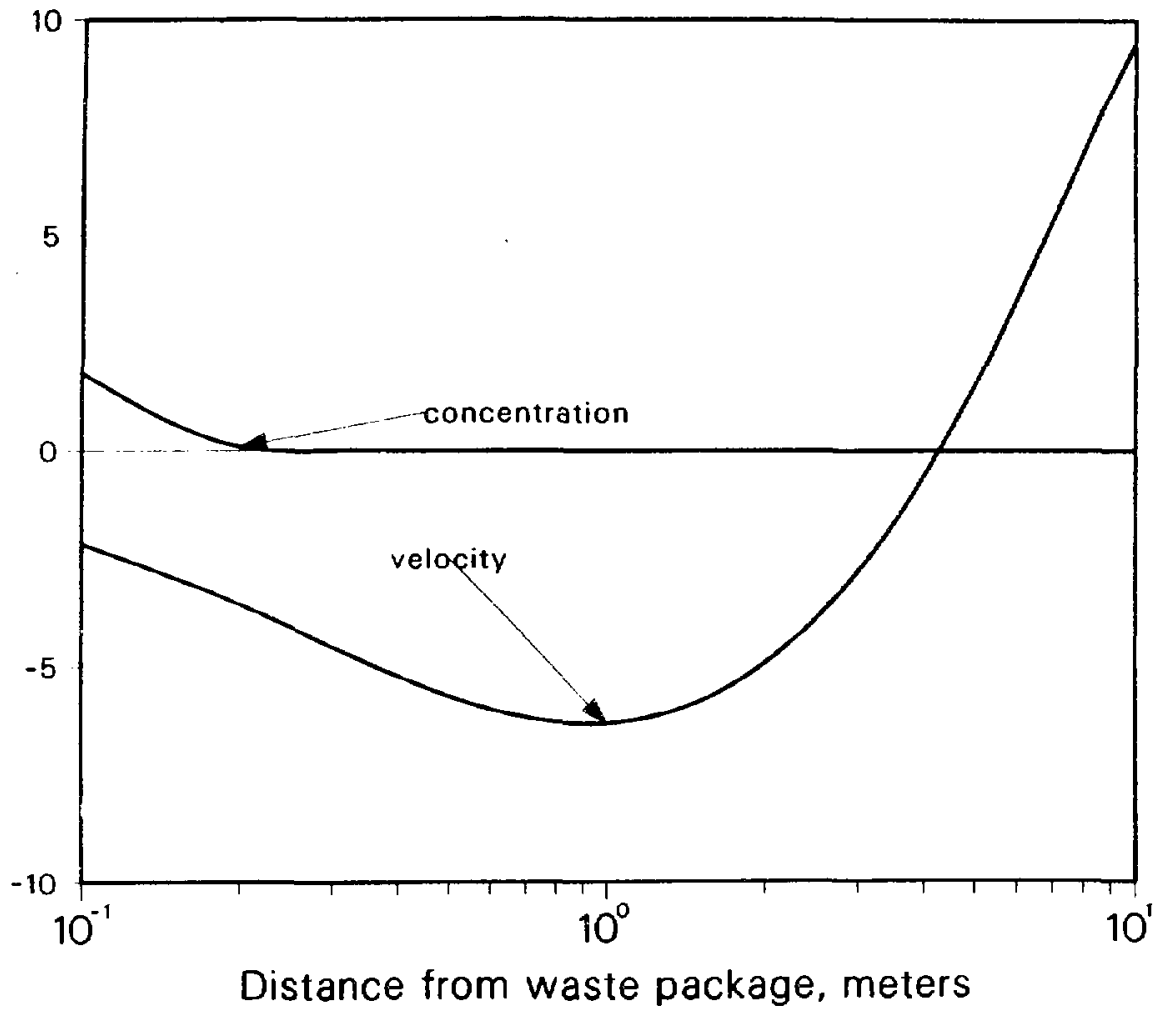

Figure 12. Relative Concentration and Velocity at Ten Years Since Emplacement 
The advective mass flux is proportional to the product of these two curves. The brine velocity is negalive in the immediate vicinity of the waste surface. Hence the product of the concentration and the migration velocity is negative, making the mass flux negative. However, this negative mass flux does not occur at the surface of the wasio.

\section{Conclusions}

We present in this report an analysis of pressure-driven brine migration in salt. We consider a high-level waste package emplaced in a borehole in salt and backfilled with salt. After few years later salt has consolidated around the waste package. After consolidation brine migration analysed by these equations and using the particular set of parameter values is of a small magnitude, with Darcy velocities of the order of nicrons per year. Advective transport of dissolved contaminants by brine migration is slow compared to diffusive transport in consolidated salt. Brine migration in consolidated salt is very localized, within a few meters from the waste package, and highly transient, fading to even lower velocities within about ten years.

Therefore. we conclude that in geologic repositories of nuclear waste where salt creep is expected to consolidate around high-level waste packages within a few years after emplacement, pressure-driven brine migration appears not to be inportant in determining compliance with U.S. Nuclear Regulatory Commission's release rate requirement. ${ }^{12}$ For the purpose of determining relase rates it appears realistic to apply previously developed analytical tools for analyzing releases from waste packages in salt repositories. ${ }^{13}$ We have published such result $\mathrm{s}^{14}$ and a report. On that subject is published separately. ${ }^{11}$

\section{References}

1. J. D. Bredehooft, "Will Salt Repositories Be Dry?" Eos, 69, 121, 1988.

2. D. F. Mr'Tigue, "Thermoelastic Response of Fluid-Saturated, Porous Rock," J. Geophy. Res., gI, B9, (9533. 1986.

3. T. Brandshaug, Estimate of Consalidation of Crushed Salt Around a Spent Fuel Waste Package, RE/SI'EC'Report RSI-315, 1987.

1. I. H. Pigford and P. L. Chanbré, "Mass Transfer in a Salt Repository," Report LBL-19918, 1985.

5. Y. Hwang, F. L. Chambré, W. W.-L. Lee and T. H. Pigford, "Pressure-Induced Brine Migration into as Open Borehole in a Salt Repository," Trans. Am. Nuc. Soc., 55, 133, 1987.

6. Y. Hwang. P. L. Chambré, W. W.-L. Lee and T. H. Pigford, "Pressure-Induced IBrine Migration in Consolidated Salt in a Repository," Thans. Am. Nuc. Soc., 55, 132, 1987

7. J. ('ossar and A Erdelyi (compilers), Dictionary of Laplace Transforms, London, Aduirality ('omputing Service. Department of Scientific Research and Experiment, 1944.

8. Westinghouse, Waste Package Reference Canceptual Design for a Repository in Sialt, Riport ON[W]$517,1986$.

9. U.S. Department of Fnergy, Enmranmental Assessment, Deaf Smith Couniy tiste, Trxas, DOF/RWV0069.1986

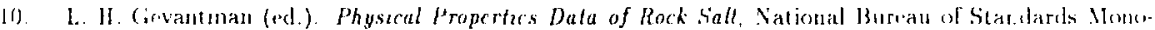


graph $167,1981$.

11. Y. Hwang. P. I.. Chambré, T. II. Pigford and W. W.-L. Lee, Radonuchde Rrlease Rates in Sall by Diffusion, Report LBL-25767, 1988.

12. U. S. Nuclear Regulatory Conmission, Disposal of High-Level Radioactive Wastes in (ieologic Repositories, $10 \mathrm{Cod}^{-1}$ of Federal Regulations $60.113(\mathrm{a})(1)(\mathrm{ii})(\mathrm{B})$.

13. T. H. Pigford and P. L. Chambré, "Radionuclide Transport in Geologic Repositories: A Review," in M. J. Apted and R. E. Westerman (cds.), Sctenlific Basts for Nuclear Wastc Management XI. Pittsburgh, Materials Rescarch Socicty, 125, 1988 .

14. P. L. Chambre, Y. Hwang, W. W.-L. Lee and T. H. Pigford, "Release Rates fron Waste Packages in a Salt Repository," Trans. Am. Nuc. Sioc., 55, 131, 1987. 